\title{
Decadal Variations of North Atlantic Sea Surface Temperature in Observations and CMIP3 Simulations*
}

\author{
NATHAN JAMISON AND SERGEY KraVtSOV \\ Atmospheric Science Group, Department of Mathematical Sciences, University of Wisconsin-Milwaukee, Milwaukee, Wisconsin
}

(Manuscript received 28 December 2009, in final form 19 April 2010)

\begin{abstract}
This study evaluates the ability of the global climate models that compose phase 3 of the Coupled Model Intercomparison Project (CMIP3) to simulate intrinsic decadal variations detected in the observed North Atlantic sea surface temperature (SST) record via multichannel singular spectrum analysis (M-SSA). M-SSA identifies statistically significant signals in the observed SSTs, with time scales of 5-10,10-15, and 15-30 yr; all of these signals have distinctive spatiotemporal characteristics and are consistent with previous studies.

Many of the CMIP3 twentieth-century simulations are characterized by quasi-oscillatory behavior within one or more of the three observationally motivated frequency bands specified above; however, only a fraction of these models also capture the spatial patterns of the observed signals. The models best reproduce the observed quasi-regular SST variations in the high-frequency, 5-10-yr band, while the observed signals in the intermediate, 10-15-yr band have turned out to be most difficult to capture. A handful of models capture the patterns and, sometimes, the spectral character of the observed variability in the two or three bands simultaneously.

These results imply that the decadal prediction skill of the models considered-to be estimated within the CMIP5 framework-would be stratified according to the models' performance in capturing the time scales and patterns of the observed decadal SST variations. They also warrant further research into the dynamical causes of the observed and simulated decadal variability, as well as into apparent differences in the representation of these variations by individual CMIP3 models.
\end{abstract}

\section{Introduction}

Decadal and interdecadal sea surface temperature (SST) variations in the North Atlantic have long been known to have a major impact on climate throughout the world, especially over the Northern Hemisphere (Delworth et al. 2007). They have been linked to changes in Atlantic hurricane activity (Mann and Emanuel 2006), droughts in the Sahel region of Africa (Rotstayn and Lohmann 2002), Indian subcontinent monsoon rains (Zhang and Delworth 2006), summer climate conditions over North America and Europe (Zhang et al. 2007), climate variability in the eastern Mediterranean region

\footnotetext{
* Supplemental information related to this paper is available at the Journals Online Web site: http://dx.doi.org/10.1175/ 2010JCLI3598.s1.

Corresponding author address: Sergey Kravtsov, Atmospheric Science Group, Dept. of Mathematical Sciences, University of Wisconsin-Milwaukee, P.O. Box 413, Milwaukee, WI 53201. E-mail:kravtsov@uwm.edu
}

(Kondrashov et al. 2005; Feliks et al. 2010), and El NiñoSouthern Oscillation (ENSO) variability (Dong et al. 2006). Because of the importance of North Atlantic SST variability in overall climate patterns, it is crucial that global climate models accurately reproduce the observed decadal SST variations characteristic of the North Atlantic.

The coupled climate models used by the Intergovernmental Panel on Climate Change (IPCC) have previously been evaluated using several different approaches. One approach consists of using conventional statistics to measure the similarity between observed and modeled datasets. For example, Taylor (2001) and Boer and Lambert (2001) ranked models using correlation, root-mean-square error, and variance ratio grouped into a single index. Other comparison approaches include that of Murphy et al. (2004), who introduced a composite error encompassing a broad range of variables, and the Bayesian approach of Min and Hense (2006). Yet other approaches include evaluating the models based on their ability to accurately forecast certain climate features such as the annual tropical temperature cycle (Lin 2007), the El NiñoSouthern Oscillation (Guilyardi 2006), ocean heat uptake 
(Dufresne and Bony 2008), the Asian-Australian monsoon (Zhou et al. 2009), summer precipitation over the United States and Mexico (Mo et al. 2005), and the equatorial cold tongue (Sun et al. 2006). In addition, DelSole (2006) studied optimal-persistence patterns (DelSole 2001) of the observed and simulated surface temperature datasets, while Jun et al. (2008) used local eigenvalue analysis to test for correlated spatial errors among the models.

The purpose of this paper is to evaluate the models' ability to accurately simulate the interannual-tointerdecadal SST variations in the North Atlantic. The following presentation is organized as follows. Section 2 describes the observational and simulated SST datasets and outlines the analysis methods used in this study. We use multichannel singular spectrum analysis (M-SSA; Ghil et al. 2002) to identify the characteristic time scales and patterns of broadband-periodic SST variations. This analysis is an update of a similar study by Moron et al. (1998), with the focus on 8- and 13-yr signals reported there, as well as a 22-yr signal consistent with the findings of Ghil and Vautard (1991) and Kravtsov et al. (2008). Interannual-to-interdecadal SST patterns have also been previously detected in numerous observational and modelanalysis studies (Sutton and Allen 1997; Delworth and Mann 2000; Dong and Sutton 2005, among others). Section 3 analyzes the performance of the global coupled general circulation models (CGCMs) in simulating the North Atlantic SST variability in the three bands identified by the observational analysis, namely highfrequency 5-10-yr, intermediate-frequency 10-15-yr, and low-frequency $15-30$-yr bands. This analysis uses the output of the twentieth-century simulations from phase 3 of the World Climate Research Programme's (WCRP) Coupled Model Intercomparison Project (CMIP3) multimodel dataset (Meehl et al. 2007), with the "accuracy" of each simulation being measured by comparing the variances and patterns of the observed versus modeled decadal variations. These results are summarized and discussed in section 4. Supplemental materials related to this paper and available online (http://dx.doi.org/10.1175/ 2010JCLI3598.s1) address the sensitivity of the M-SSA spectra to window size, contain the results of M-SSA analysis based on Rayner et al.'s (2006) SST dataset, and provide some further details on the pattern comparison between the modes of decadal variability simulated by CMIP3 models with the observed signals.

\section{Data and methodology}

\section{a. Datasets}

This paper uses two sources of SST observations. The first is an updated version of Kaplan et al.'s Northern
Hemisphere extended SST anomaly dataset (Kaplan et al. 1998), which consists of monthly data on a $5^{\circ} \times 5^{\circ}$ grid, covering the period from December 1856 to November 2007 , in the North Atlantic region $\left(10^{\circ}-80^{\circ} \mathrm{N}, 120^{\circ} \mathrm{E}-0^{\circ}\right)$. The second observational dataset is the Hadley Centre Sea Surface Temperature (HadSST2) variance-adjusted version of the $5^{\circ} \times 5^{\circ} \mathrm{SST}$ dataset (Rayner et al. 2006).

We analyzed model datasets based on the twentiethcentury simulations $(20 \mathrm{C} 3 \mathrm{M})$ performed by various modeling groups within phase 3 of the World Climate Research Programme's (WCRP) Coupled Model Intercomparison Project [CMIP3; see Meehl et al. (2007) for background information and visit the IPCC/CMIP3 Web site (http://www-pcmdi.llnl.gov/ipcc/model_documentation/ ipcc_model_documentation.php) for model documentation]. There are a total of 24 different CMIP3 climate models that provide SST output. For this paper, we only used the 22 of them that had no missing data in the North Atlantic region during the twentieth century; see Table 1 for a list of the models, as well as for the starting and ending dates of each model simulation. Several of the models simulated multiple realizations of the twentiethcentury climate, but for the present analysis we only used one realization for each model.

\section{b. Methodology}

\section{1) DATA PREPROCESSING}

We considered the wintertime-mean SST values for each year (December-March). The focus on wintertime SST anomalies was motivated by an implicit assumption that coupled ocean-atmosphere dynamics may be important for the decadal and interdecadal variabilities considered here (see, e.g., Kravtsov et al. 2008); such coupled feedbacks centrally involve the atmospheric teleconnections patterns, which are most pronounced in winter (Wallace et al. 1993). However, we have confirmed that the decadal signals identified by our analyses are also present in the annual-mean SST time series (see section 3a).

We then compressed the linearly detrended SST data via empirical orthogonal function (EOF) analysis (Preisendorfer 1988) and used the leading six principal components (PCs) as the "channels" of the vector time series to be analyzed by M-SSA (Ghil et al. 2002); see subsection 2 below. For both the observation data and the model output, the SST data were weighted by the square root of the cosine of the latitude prior to EOF analysis to account for meridian convergence. The sixth of the leading PCs to use in the M-SSA analysis was determined by trial and error to give the most consistent results for the observational data in terms of the dominant decadal oscillations' sensitivity to the M-SSA window 
TABLE 1. The CMIP3 official model names, abbreviations, countries of origin, and starting and ending dates used in the present analysis.

\begin{tabular}{|c|c|c|c|}
\hline Originating group(s) & Model name (CMIP3 identification) & Country & Time period \\
\hline Bjerknes Centre for Climate Research & $\begin{array}{l}\text { Bergen Climate Model, version } 2.0 \\
\text { (BCCR-BCM2.0) }\end{array}$ & Norway & $1871-2003$ \\
\hline National Center for Atmospheric Research (NCAR) & $\begin{array}{l}\text { Community Climate System Model, } \\
\text { version } 3 \text { (CCSM3) }\end{array}$ & United States & $1871-1999$ \\
\hline $\begin{array}{l}\text { Canadian Centre for Climate Modeling and } \\
\text { Analysis (CCCma) }\end{array}$ & $\begin{array}{l}\text { Coupled General Circulation Model, } \\
\text { version } 3.1 \text { [CGCM3.1(T47)] }\end{array}$ & Canada & $1871-2000$ \\
\hline CCCma & CGCM3.1(T63) & Canada & $1871-2000$ \\
\hline $\begin{array}{l}\text { Météo-France/Centre National de Recherches } \\
\text { Météorologiques }\end{array}$ & $\begin{array}{l}\text { Coupled Global Climate Model, version } 3 \\
\text { (CNRM-CM3) }\end{array}$ & France & 1871-1999 \\
\hline $\begin{array}{l}\text { Commonwealth Scientific and Industrial Research } \\
\text { Organisation (CSIRO) Atmospheric Research }\end{array}$ & Mark version 3.0 (CSIRO-Mk3.0) & Australia & $1872-2000$ \\
\hline CSIRO Atmospheric Research & Mark version 3.5 (CSIRO-Mk3.5) & Australia & $1872-2000$ \\
\hline Max Planck Institute for Meteorology & Ocean Model (ECHAM5/MPI-OM) & Germany & $1871-2000$ \\
\hline $\begin{array}{l}\text { Meteorological Institute of the University of Bonn, } \\
\text { Meteorological Research Institute of the Korea } \\
\text { Meteorological Administration (KMA), and the } \\
\text { Model and Data Group }\end{array}$ & $\begin{array}{l}\text { ECHAM and the global Hamburg } \\
\text { Ocean Primitive Equation (ECHO-G) }\end{array}$ & Germany, Korea & $1871-2000$ \\
\hline $\begin{array}{l}\text { State Key Laboratory of Numerical Modelling for } \\
\text { Atmospheric Sciences and Geophysical Fluid } \\
\text { Dynamics (LASG)/Institute of Atmospheric Physics }\end{array}$ & $\begin{array}{l}\text { Flexible Global Ocean-Atmosphere-Land } \\
\text { System Model gridpoint version } 1.0 \\
\text { (FGOALS-g1.0) }\end{array}$ & China & $1871-1999$ \\
\hline $\begin{array}{l}\text { National Oceanic and Atmospheric Administration/ } \\
\text { Geophysical Fluid Dynamics Laboratory } \\
\text { (NOAA/GFDL) }\end{array}$ & Climate Model version 2.0 (GFDL-CM2.0) & United States & $1871-2000$ \\
\hline NOAA/GFDL & Climate Model version 2.1 (GFDL-CM2.1) & United States & $1871-2000$ \\
\hline $\begin{array}{l}\text { National Aeronautics and Space Administration } \\
\text { Goddard Institute for Space Studies (NASA GISS) }\end{array}$ & Atmosphere-Ocean Model (GISS-AOM) & United States & $1871-2000$ \\
\hline NASA GISS & Model E-H (GISS-EH) & United States & 1881-1999 \\
\hline NASA GISS & Model E-R (GISS-ER) & United States & $1881-2003$ \\
\hline Instituto Nazionale di Geofisica e Vulcanologia & Scale Interaction Experiment (INGV-SXG) & Italy & $1871-2000$ \\
\hline Institute for Numerical Mathematics & Coupled Model, version 3.0 (INM-CM3.0) & Russia & \\
\hline Institut Pierre Simon Laplace & Coupled Model, version 4 (IPSL-CM4) & France & $1871-2000$ \\
\hline $\begin{array}{l}\text { Center for Climate System Research, University of } \\
\text { Tokyo; the National Institute for Environmental } \\
\text { Studies; and Frontier Research Center for } \\
\text { Global Change (JAMSTEC) }\end{array}$ & $\begin{array}{l}\text { Model for Interdisciplinary Research on } \\
\text { Climate 3.2, high-resolution version } \\
\text { [MIROC3.2(hires)] }\end{array}$ & Japan & $1871-2000$ \\
\hline $\begin{array}{l}\text { Center for Climate System Research, National } \\
\text { Institute for Environmental Studies, and JAMSTEC }\end{array}$ & $\begin{array}{l}\text { MIROC3.2 medium-resolution version } \\
\text { [MIROC3.2(medres)] }\end{array}$ & Japan & $1871-2000$ \\
\hline Meteorological Research Institute & $\begin{array}{l}\text { Coupled General Circulation Model, } \\
\text { version 2.3.2a (MRI-CGCM2.3.2) }\end{array}$ & Japan & $1871-2000$ \\
\hline NCAR & Parallel Climate Model (PCM) & United States & 1891-1999 \\
\hline
\end{tabular}

size, and the same number was used for the model data for consistency.

\section{2) MultichanNEl Singular SPECTRUM ANALYSIS (M-SSA)}

The sequences and patterns of warming and cooling in both the historical and model datasets are difficult to predict, due to the presence of intrinsic climate variability on a wide range of time scales. While much of this natural variability can be described as red noise (Hasselmann 1976), there are identifiable quasi-regular signals embedded in the noise background. Singular spectrum analysis is one of the statistical tools designed for the detection of such signals in a time series; the multivariate version of SSA (Broomhead and King 1986; Elsner and Tsonis 1996; Ghil et al. 2002) has been extensively used to examine intrinsic periodicities in surface temperature and other climatic time series (Vautard and Ghil 1989; Ghil and Vautard 1991; Allen 1992; Vautard et al. 1992; Keppenne and Ghil 1993; Plaut and Vautard 1994; Plaut et al.1995; Moron et al. 1998; Ghil et al. 2002). Separation and identification of quasi-regular decadal trends would permit a better attribution of the anthropogenic effects or other external factors in the warming trend experienced over the past several decades, as well as the determination of whether coupled climate models are well disposed to capture these warming and cooling patterns and their time scales, with implications for decadal climate predictability. 
M-SSA diagonalizes the lag-covariance matrix of a given multichannel time series in the same way that the EOF analysis diagonalizes the lag-zero covariance matrix. The lags used a range from 0 to $M-1$, where the window width $M$ determines the range of periodicities to be detected. The eigenvectors of the resulting matrix are called time-EOFs (T-EOFs), and the projections of T-EOFs onto the extended time series consisting of the original time series and its lagged copies are called timePCs (T-PCs). M-SSA identifies an oscillatory as a pair of T-PCs of similar-and large, that is, above the 95th percentile of the corresponding red-noise surrogatesvariance, in phase quadrature and corresponding to the same frequency. The broadband oscillations are usually represented by a few pairs (not all of which are necessarily statistically significant), with the dominant, most statistically significant pair corresponding to the largest variance defining the center period of the oscillation, and the frequency spread between the pairs being related to the oscillation's bandwidth. For each significant dominant M-SSA pair-or M-SSA mode—so identified, we made sure that the periodicity detected is not a sampling artifact by varying the M-SSA window size $M$, and ensuring that the statistically significant pair occurs at the same frequency for a broad range of $M$ values (see the supplemental materials for this paper).

The evolution of each quasi-oscillatory M-SSA mode in the original space is given by its reconstructed component (RC). The RCs effectively represent a narrowband version of the multivariate time series under consideration, in which the filters are related to the coefficients of this time series' M-SSA decomposition; the RCs are not mutually orthogonal, but the sum of the RCs across all of the M-SSA modes is identical to the original time series. We will use the RCs to describe and compare the patterns associated with each mode's variability in observations and climate models. In particular, we will (i) study consecutive snapshots (in physical space) of a given M-SSA mode RC and (ii) perform EOF analysis of the $\mathrm{RC}$ time series to determine the spatial patterns that dominate the variability of each quasi-oscillatory M-SSA mode.

\section{3) COMPARING OBSERVED AND MODELED OSCILLATIONS}

The M-SSA analysis of observed SST anomalies presented in section 3a identifies three distinct oscillations with time scales centered about the periods of 7.5, 13, and $22 \mathrm{yr}$. To compare the observed and simulated SST variabilities, we considered three frequency bands, which corresponded to the quasi-periodic signals above, namely 5-10, 10-15, and 15-30 yr. First, we compared the spatial patterns of the RCs for the dominant statistically significant M-SSA mode (if detected in this frequency band) with the corresponding observed patterns. Not all of the models simulated variability characterized by statistically significant signals in all (or, in some cases, any) of the three frequency bands. Therefore, to broaden the scope of our analysis, we next considered and compared the observed and simulated variabilities by applying 5-10-, 10-15-, and 15-30-yr bandpass filters to these datasets. The results reported below were obtained using the bandpass filter developed by Christiano and Fitzgerald (1999); the results based on the use of a Lanczos filter are essentially the same (nor shown). The major difference between the time series so filtered and the M-SSA mode's RCs is in that the latter represent the variability filtered in a narrower band about the center frequency than the former. We then computed, for each model and each frequency band, the absolute value of the spatial correlation between the leading EOFs of the observed and simulated filtered data, as well as the ratio of the absolute variances accounted for by these EOFs. The "best" models would thus ideally have both their spatial correlation and variance ratios close to unity.

\section{Results}

\section{a. Observed SST anomalies}

For the Kaplan et al. (1998) SST dataset, the leading 6 EOF modes jointly account for about $85 \%$ of the total SST variance, while the same number of EOFs account for about $77 \%$ of the variance in the Rayner et al. (2006) dataset. The three leading EOFs for the former dataset are shown in Fig. 1. The first EOF is dominated by a dipole pattern off the east coast of the United States, with the dipole axis collocated with the time-mean Gulf Stream position, and an accompanying monopole off the west coast of Africa; the corresponding PC (not shown) has, in addition to pronounced decadal variability, a fairly substantial multidecadal component related to the Atlantic multidecadal oscillation (AMO; see, e.g., Enfield et al. 2001). EOFs 2 and 3 exhibit tripolar and dipolar patterns in the North Atlantic; their corresponding PCs (not shown) are characterized, similarly to PC-1, by vigorous interannual-to-interdecadal variability. The three leading EOFs of the SSTs based on the Rayner et al. analysis are similar (not shown).

Previous observational and modeling results argue for the presence of decadal and interdecadal climate modes rooted in the ocean or the coupled dynamics of the North Atlantic region (see Kravtsov et al. 2008 for a brief review); therefore, we will use a priori confidence levels to assess the statistical significance of the spectral peaks below. The M-SSA spectrum of the six leading PCs of 
(a)

\section{EOF-1}

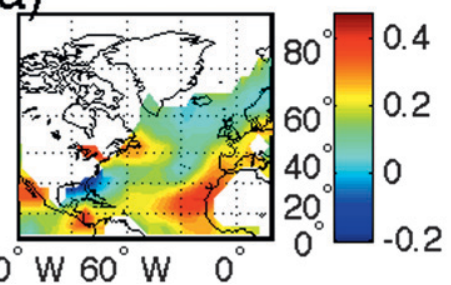

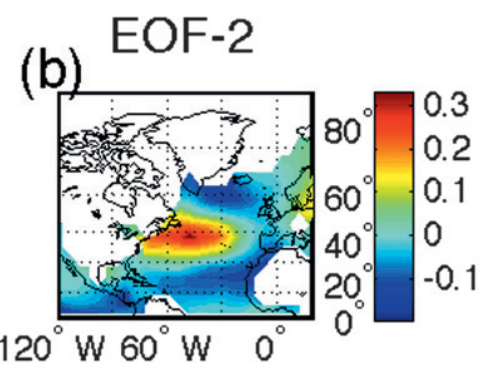

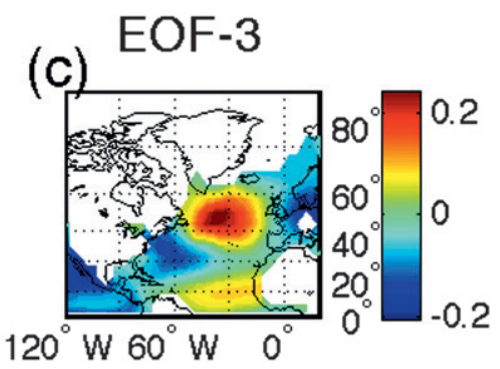

FIG. 1. Leading EOFs (computed as projections of raw SST anomalies onto the corresponding normalized PCs; ${ }^{\circ} \mathrm{C}$ ) of North Atlantic SST data (Kaplan et al. 1998).

the Kaplan et al. SST dataset (Fig. 2) detects three dominant statistically significant pairs corresponding to the periods of 22,13 , and $7.5 \mathrm{yr}$. The latter two oscillations were found to be robust with respect to the window size $M$, for $20 \leq M \leq 60$, while the identification of the former, lowest-frequency oscillation required a window size exceeding $M \geq 30$ (see the supplemental materials for this paper). For the Rayner et al. SST data, the M-SSA spectrum reveals analogous statistically significant pairs, corresponding to the periods of 21, 13, and 6 yr (see the supplemental materials for this paper). The latter two oscillations were detected by examining the annual wintertime mean, as was the case with the Kaplan et al. data. To identify the statistically significant 21 -yr oscillation in the generally noisier SST dataset based on the Rayner et al. analysis, we had to elevate the signal-to-noise ratio by filtering out the higher-frequency oscillations using a 3-yr boxcar running averages prior to performing the M-SSA.

To illustrate the statistical significance of the spectral peaks identified by the M-SSA analysis, as well as the robustness of these peaks with respect to the season

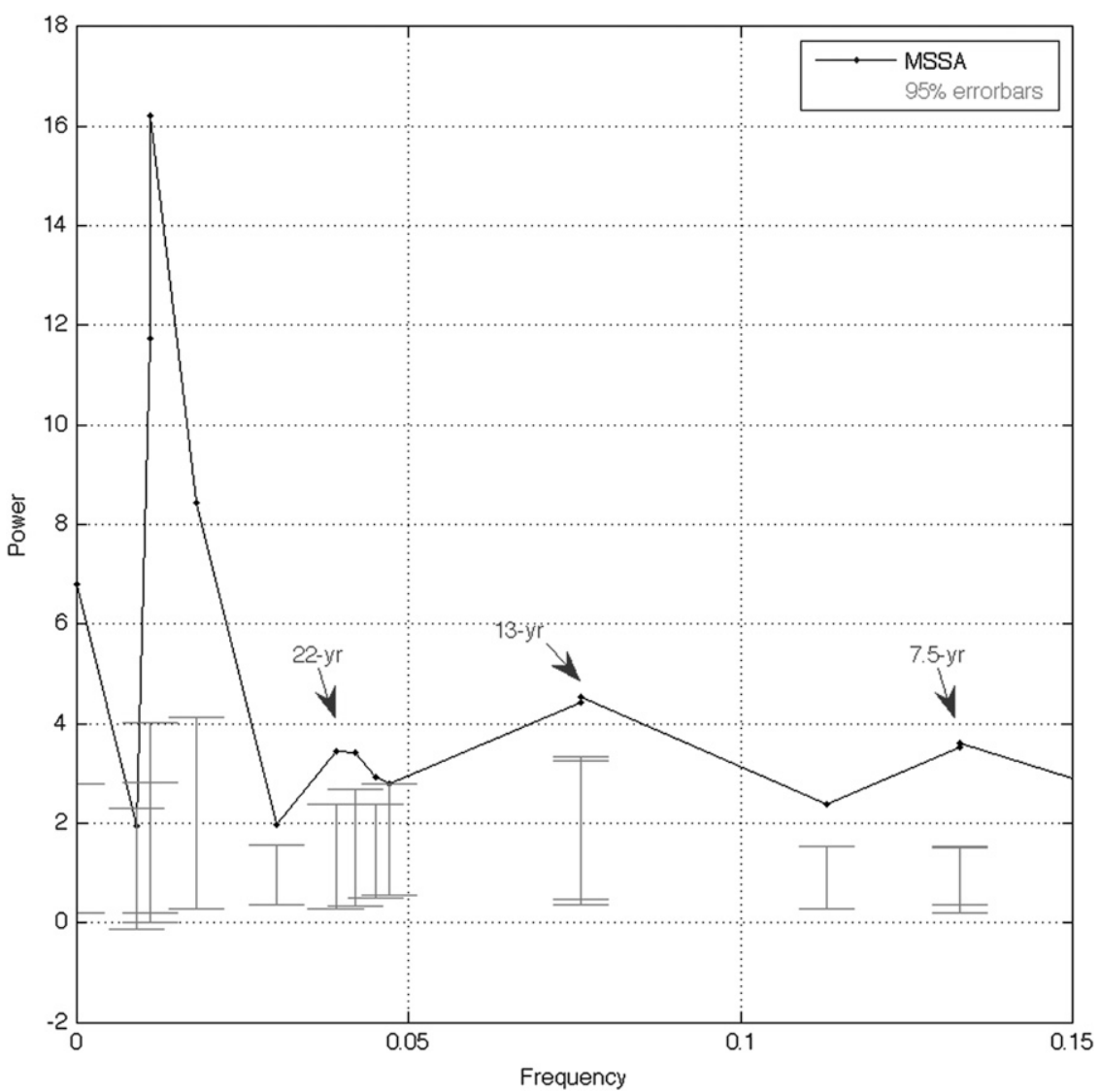

FIG. 2. M-SSA spectrum of the leading 6 PCs of wintertime North Atlantic SST data with $95 \%$ error bars. Window size $N=60$. 
(a) SST PC-1 spectrum

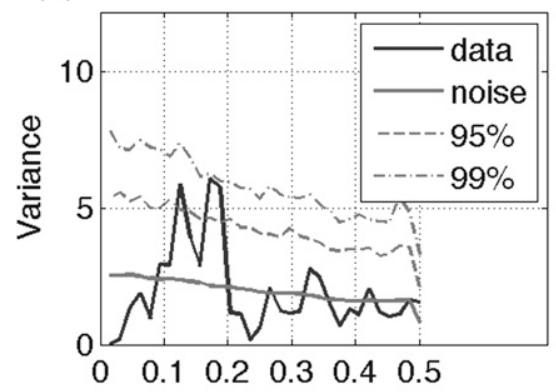

(c)

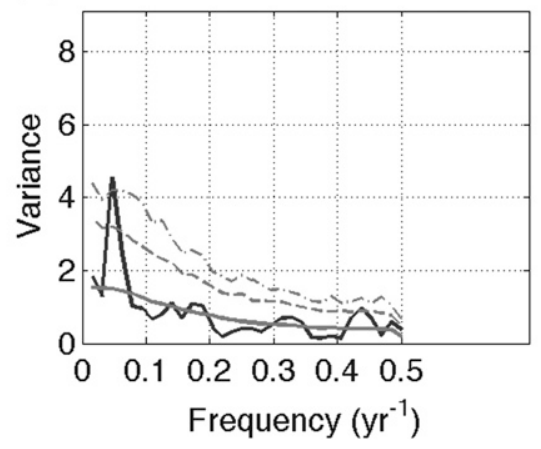

(b) SST PC-2 spectrum

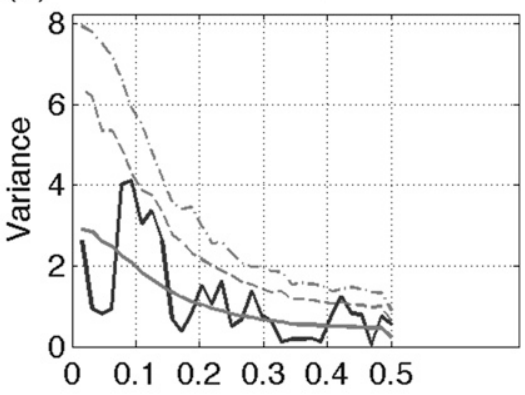

(d) SST PC-4 spectrum

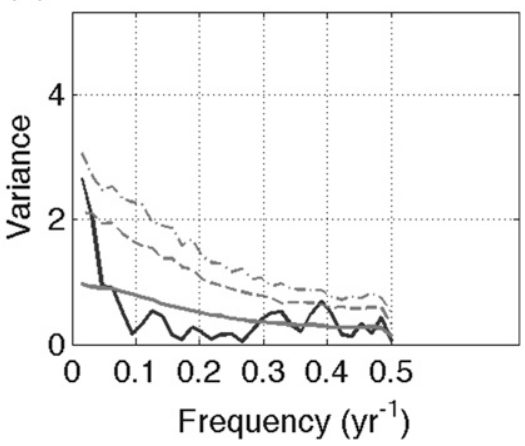

FIG. 3. Fourier spectra of the leading 4 PCs of the linearly detrended annual-mean Kaplan SST (1856-2007) with $95 \%$ and $99 \%$ error plots. The more jagged line is the data and the smoother line is the noise The spectra were computed using the Welch periodogram method; significance levels are based on 1000 realizations of a one-dimensional red-noise model fitted to each PC considered. The leading SST PC (PC-1) was high-pass filtered by subtracting the leading RC pair from its SSA analysis; this (removed) low-frequency signal is well correlated with the AMO (Enfield et al. 2001).

analyzed, we have also computed traditional Fourier spectra of the annual-mean SST data using the Welch periodogram method (Press et al. 1992). These spectra were computed for four leading PCs of the linearly detrended annual-mean 1856-2007 SST anomalies. To concentrate on the decadal scales, PC-1 was also high-pass filtered by subtracting the leading RC pair of its SSA decomposition; the latter RC pair is well correlated with the AMO index (Enfield et al. 2001). The resulting spectra, along with red-noise-based estimates of the significance levels, are shown in Fig. 3. PC-1 exhibits statistically significant spectral peaks in the 5-10-yr range; PC-2 has an elevated spectral power in the decadal range, albeit with magnitude not quite reaching the $5 \%$ significance level; PC-3 has a spectral peak at about 20 -yr period; and PC-4 is dominated by multidecadal variability. These results demonstrate an apparent overlap between the spectral features of the SST data determined via M-SSA and traditional Fourier spectral analyses. The advantage of M-SSA over the traditional Fourier analysis is in the former method's ability to distinguish between the modes of variability with distinct spatial signatures, which enhances the robustness (statistical significance) of the signals identified. The M-SSA reconstruction allows one to visualize the spatiotemporal evolution of these signals.

A reconstruction of the 7.5-yr oscillation of the Kaplan et al. data over a select 9-yr period is shown in Fig. 4. The primary feature of this oscillation's pattern is an area of warming that begins off the southeast coast of the United States and propagates northeastward along the coast and toward Iceland. During the portion of the oscillation that this warm anomaly enters the northernmost region of the North Atlantic and exhibits amplification (1961-63), warm SST anomalies develop along the west coast of North Africa. The evolution in 1961-65 has a similar pattern to that during the 1957-1961 period, albeit with anomalies of the opposite sign. We note that while the period and, to a large extent, the spatial pattern of the 7.5-yr oscillation identified here are consistent with those in the earlier analysis by Moron et al. (1998), the detailed spatiotemporal structure of this signal is different. In particular, the latter authors describe an essentially stationary oscillation (see their Fig. 10), while our analysis indicates a more complex structure, 
1957
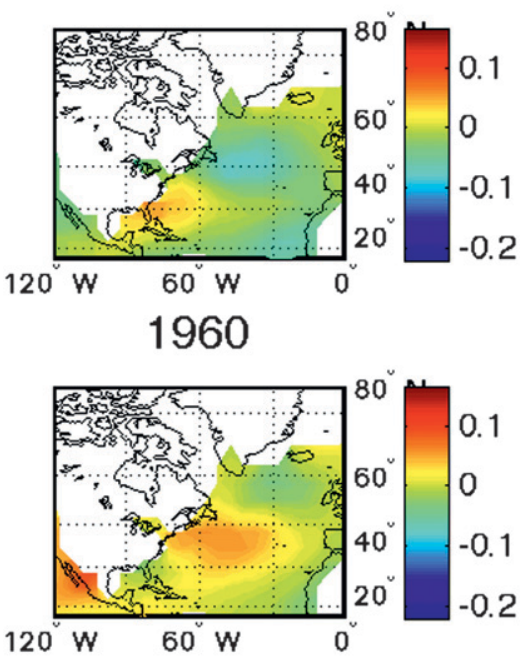

1963

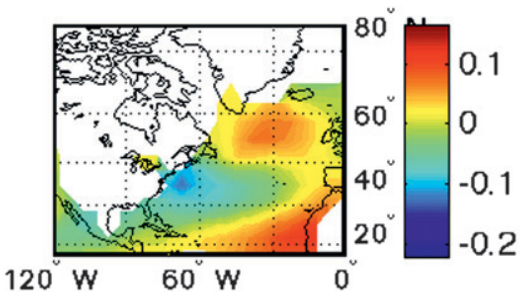

1958
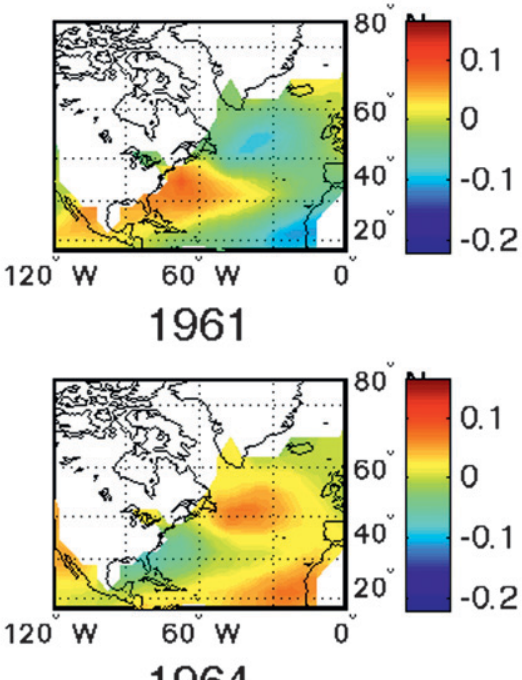

1964

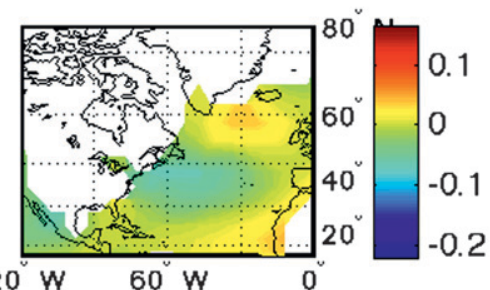

1959

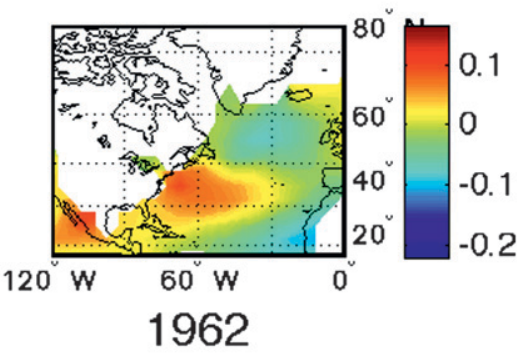

FIG. 4. The RC of the 7.5-yr SST anomaly signal $\left({ }^{\circ} \mathrm{C}\right)$, plotted over a select 9-yr period, 1957-1965.

which involves a combination of stationary and propagating characteristics.

To compactly describe the essential spatial ingredients of the above 7.5-yr signal, we performed EOF analysis of its RC-pair time series (whose short portion is shown in Fig. 4). To fully describe this signal requires three leading EOFs of the reconstructed data (Fig. 5), which describe $73 \%, 15 \%$, and $9 \%$ of the total reconstructed SST variance, respectively, and 97\% cumulatively. The first EOF is dominated by a tripolar pattern with positive values south of Greenland and Iceland and off the west coast of North Africa, and negative values off the east coast of the United States. The second EOF exhibits a similar tripolar pattern, except that the second area of positive values is located in the Caribbean rather than off of Africa. The third EOF is dominated by a monopolar pattern in the central North Atlantic. The combination of all of these three patterns (whose time series are uncorrelated at the zero lag) is necessary to account for the concurrent anomaly propagation along the eastern U.S. coast and the development of a stationary monopole off the west coast of Africa seen in Fig. 4.

The reconstruction of the 13-yr signal (nor shown) is virtually identical to that presented by Moron et al. (1998, their Fig. 9). This oscillation exhibits a stationary tripolar pattern that is represented well by the single EOF (Fig. 6),
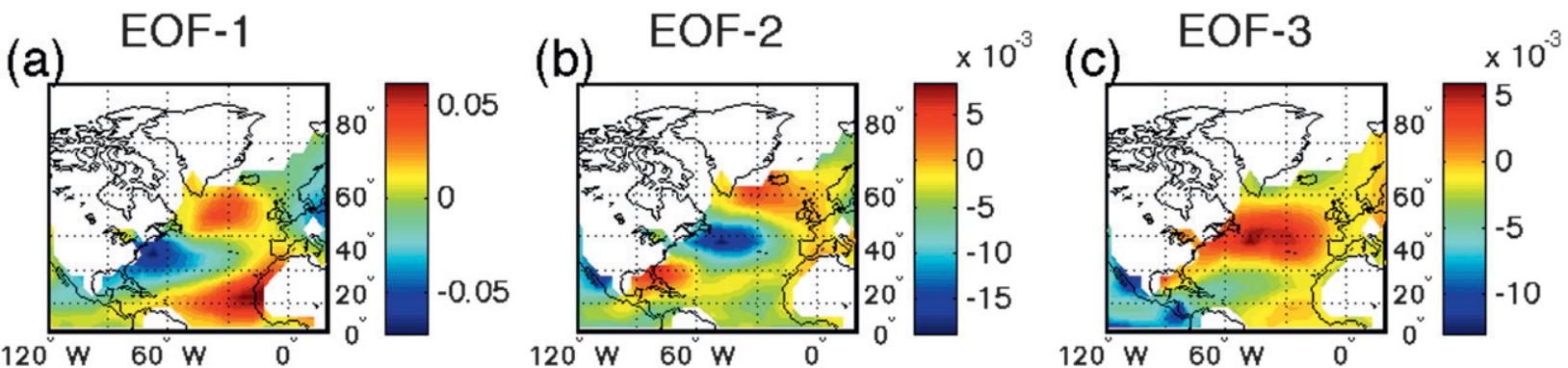

FIG. 5. The 3 leading EOFs of the 7.5-yr signal's RC. 


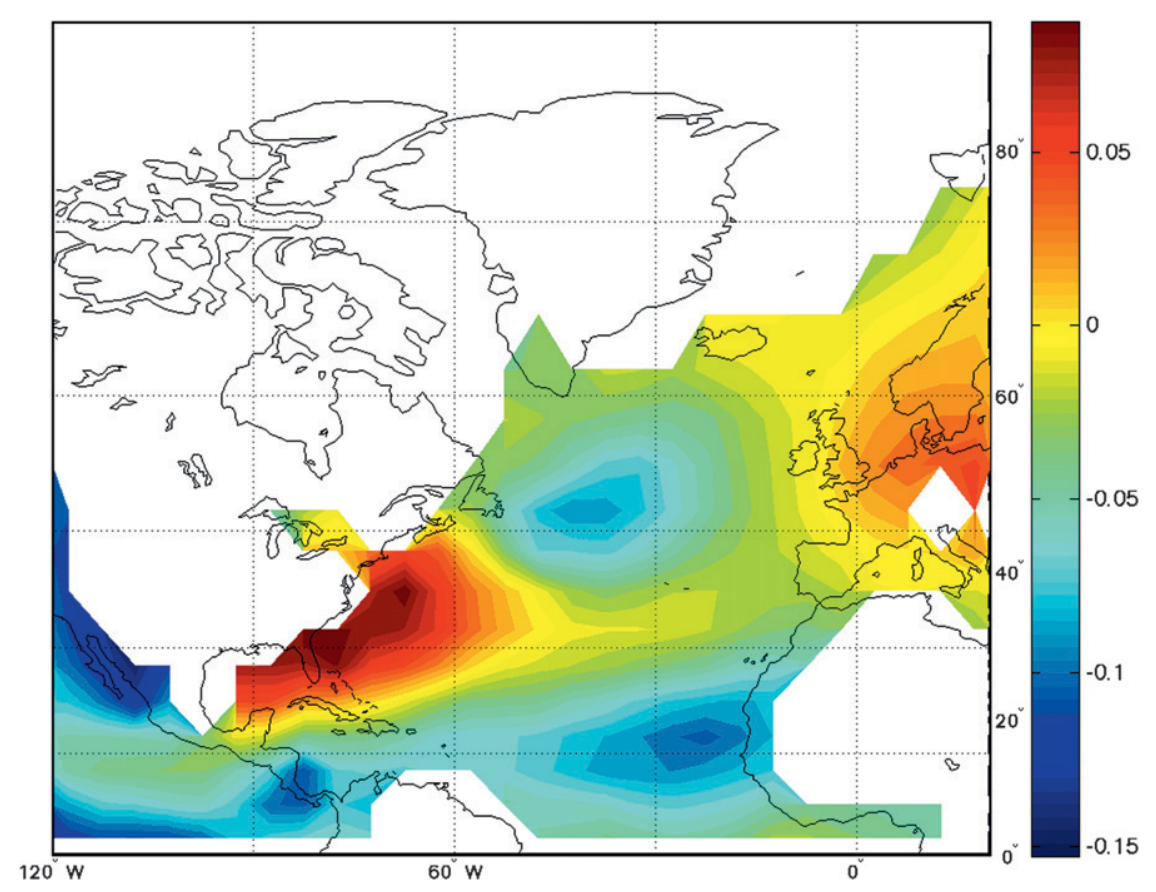

FIG. 6. As in Fig. 4, but for the 13-yr signal.

which accounts for $97 \%$ of the total reconstructed variance. This pattern is very similar to that of the leading EOF of the 7.5-yr signal (Fig. 5), except for the central lobe being less zonally pronounced (more confined in the vicinity of the east coast of United States). Note, however, that the stationary character of this variability makes it clearly distinguishable from a more complex 7.5-yr signal above. This signal is probably identical to the 9-12-yr oscillations detected in the observational studies by Deser and Blackmon (1993) and Kravtsov et al. (2008).

Figure 7 illustrates the spatial evolution of the 22-yr oscillation's reconstruction over a select 23 -yr period. The primary feature of this oscillation is a region of stationary SST anomalies located off the coast of Newfoundland. The oscillation is also accompanied by the anomaly propagation along the U.S. east coast; for example, it follows the negative anomaly off the coast of Florida in 1957 propagating to the northeast and saturating in 1963 at the location of a stationary-anomaly region. The oscillation is fully described by the two leading EOF modes (Fig. 8), which account individually for $79 \%$ and $18 \%$, and jointly for about $96 \%$, of the total reconstructed SST variance. The first EOF exhibits an area of negative values off the New England coast, to the north of the time-mean Gulf Stream, and positive values over the rest of the North Atlantic, while the second EOF shows a similar area of negative values, this time slightly to the north and farther out to sea, with an area of positive values off the southeast coast of the United States.
In summary, the above three signals all have distinct spatiotemporal characteristics. We repeated the analyses above using the Rayner et al. SST dataset, and found similar spatial EOF patterns for its reconstructed 6-, 13and 21-yr signals; however, the variance of the 21-yr oscillation was substantially weaker compared to that of the 22-yr signal based on the Kaplan et al. SST dataset (see the supplemental materials for this paper).

\section{b. CMIP3-simulated SST variability}

\section{1) M-SSA ANALYSIS}

The results of our M-SSA analysis of various CMIP3 model simulations (see Table 1) are summarized in Table 2, in which the left column lists a given model acronym, while the capital $\mathrm{X}$ symbols in the next three columns indicate whether this model-simulated SST in the North Atlantic exhibited a significant M-SSA pair in 5-10-, 10-15-, and 15-30-yr bands, respectively. Six of the models examined simulated quasi-periodic signals in all three of these observational-data-motivated frequency bands, seven of the models exhibited statistically significant oscillations in two out of the three bands, four models showed the oscillations in one out of the three bands, and, finally, three of the models did not produce oscillations in any of the three bands.

The comparison outlined in Table 2 discussed above documents whether the CMIP3 models reproduce the time scales of the observed decadal-to-interdecadal 
1957

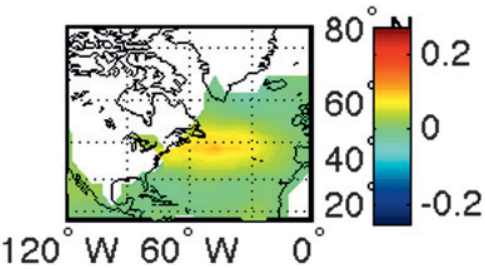

1963

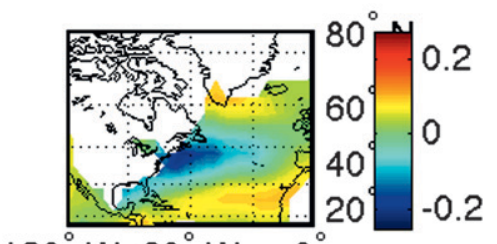

$120^{\circ} \mathrm{W} 60^{\circ} \mathrm{W} 0^{\circ}$

1969

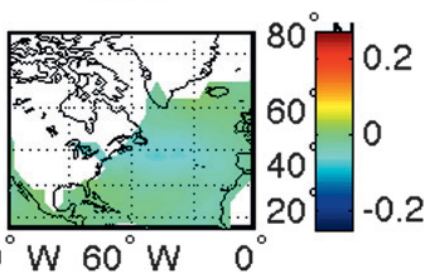

1975

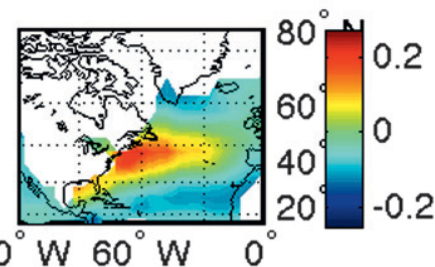

1959

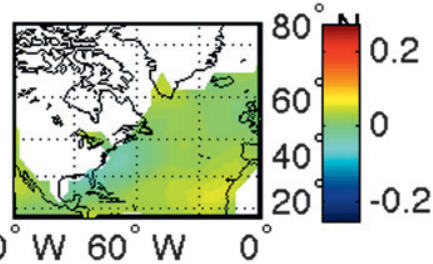

1965

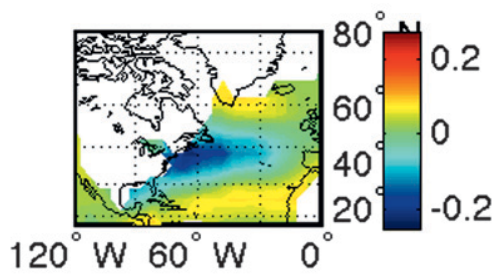

1971

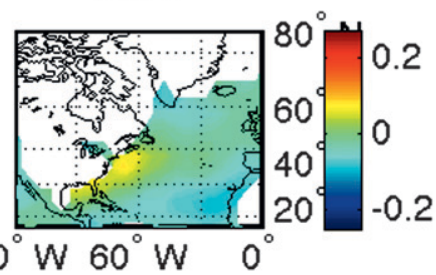

1977

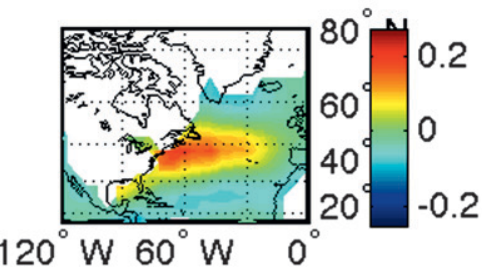

1961

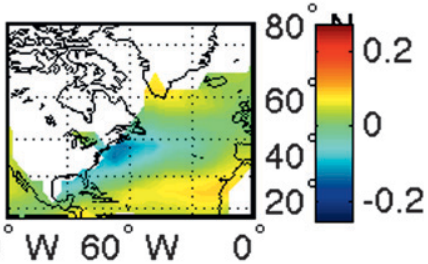

1967

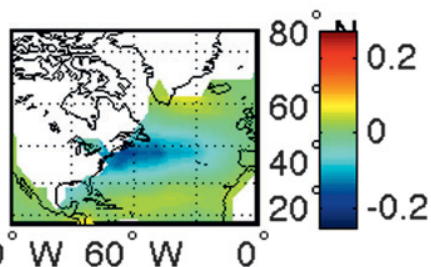

1973

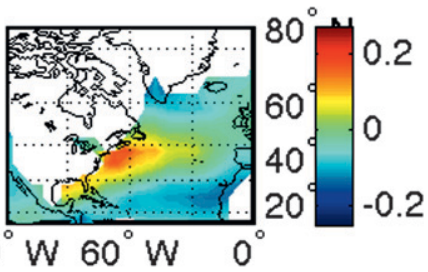

1979

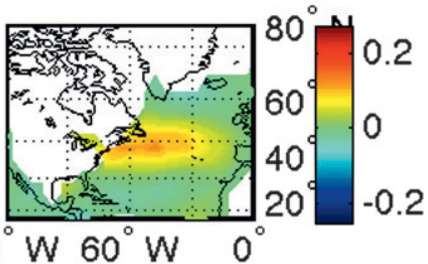

FIG. 7. The RC of the 22-yr SST anomaly signal $\left({ }^{\circ} \mathrm{C}\right)$, plotted over a select 23 -yr period, 1957-1979.

variability, but what is not addressed is whether the models capture the patterns of these signals To address this question, we computed, for each statistically significant M-SSA mode identified in the CMIP3 simulations, the reconstructed time series analogous to the RCs shown in Fig. 4 for the observed 7.5-yr signal and Fig. 7 for the observed 22-yr signal. We then computed the leading EOFs of each CMIP3-based RC pair, in the same way as (a)

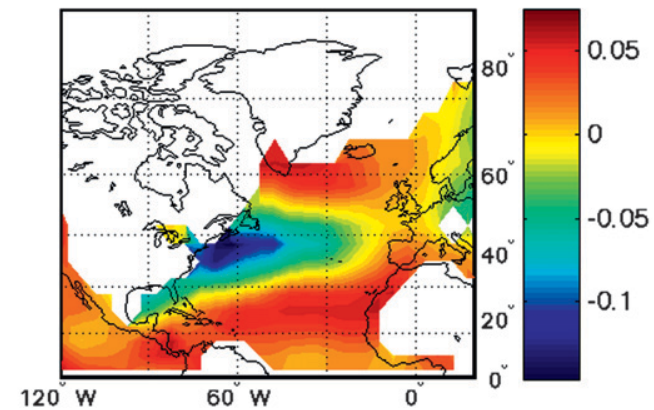

(b)

EOF-2

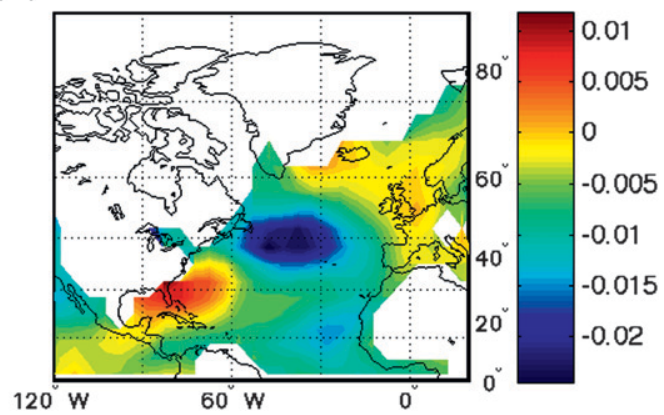

FIG. 8. The 2 leading EOFs of the 22-yr signal's RC. 
TABLE 2. Evaluation of CMIP3 model performance in reproducing the observed decadal-to-interdecadal variability. The $\mathrm{x}$ symbols indicate that the significant M-SSA mode was detected in a given model's simulation of the North Atlantic SST, and in a given frequency band of the three bands considered [see section $3 b(1)]$. The $\mathrm{O}$ symbols mark, in each band, the models whose dominant patterns of the corresponding bandpass-filtered variability are correlated with the analogous observed patterns, at the $5 \%$ significance level, while the o symbols show the models with these correlations just below the $5 \%$ threshold [see section $3 \mathrm{~b}(2)$ and Figs. 10-12].

\begin{tabular}{lccc}
\hline \multicolumn{1}{c}{ Model } & 5-10-yr band & 10-15-yr band & 15-30-yr band \\
\hline BCCR & $\mathrm{X}, \mathrm{O}$ & $\mathrm{O}$ & $\mathrm{O}$ \\
CCSM3 & $\mathrm{X}$ & $\mathrm{X}$ & \\
CGCMt47 & $\mathrm{X}, \mathrm{o}$ & $\mathrm{X}$ & $\mathrm{X}, \mathrm{O}$ \\
CGCMt63 & $\mathrm{X}, \mathrm{O}$ & $\mathrm{X}$ & \\
CNRM & $\mathrm{X}, \mathrm{O}$ & $\mathrm{X}$ & $\mathrm{X}, \mathrm{O}$ \\
CSIRO 3.0 & $\mathrm{X}$ & $\mathrm{X}$ & $\mathrm{X}$ \\
CSIRO 3.5 & & $\mathrm{X}$ & \\
ECHAM5 & & $\mathrm{o}$ & \\
ECHO-G & & & $\mathrm{O}$ \\
FGOALS & & $\mathrm{X}$ & $\mathrm{O}$ \\
GFDL 2.0 & $\mathrm{X}, \mathrm{o}$ & $\mathrm{X}, \mathrm{o}$ & $\mathrm{X}$ \\
GFDL 2.1 & $\mathrm{X}$ & $\mathrm{X}$ & $\mathrm{X}, \mathrm{O}$ \\
GISS-AOM & $\mathrm{X}$ & $\mathrm{X}$ & $\mathrm{X}$ \\
GISS-EH & $\mathrm{O}$ & & $\mathrm{O}$ \\
GISS-ER & $\mathrm{X}, \mathrm{O}$ & $\mathrm{X}$ & $\mathrm{X}$ \\
INGV & $\mathrm{X}, \mathrm{o}$ & & $\mathrm{X}$ \\
INMCM & $\mathrm{X}$ & & $\mathrm{X}$ \\
IPSL & $\mathrm{O}$ & $\mathrm{X}$ & $\mathrm{O}$ \\
MIROC(hires) & $\mathrm{X}, \mathrm{o}$ & $\mathrm{X}$ & $\mathrm{X}$ \\
MIROC(medres) & $\mathrm{X}, \mathrm{O}$ & $\mathrm{O}$ & $\mathrm{X}$ \\
MRI-CGCM & & & \\
PCM & & & \\
\hline
\end{tabular}

we did for the observations (see Figs. 5, 6, and 8 for the observed 7.5-, 13-, and 22-yr signals, respectively). The few EOF patterns that describe jointly $>95 \%$ of the total reconstructed variance compactly summarize the spatial characteristics of each simulated oscillatory signal; they should be compared with the corresponding observed patterns.

An example of the above analysis is presented in Fig. 9, which shows the patterns that describe the dominant quasi-periodic signals simulated by the CGCMt47 model (the comparison between the observed and simulated raw-data SST EOFs is included in the supplemental materials for this paper). The modeled signals have time scales of 7,11 , and $23 \mathrm{yr}$, respectively; these periods match well the observed 7.5-, 13-, and 22-yr time scales. The CGCMt47 model does a fairly decent job of recreating the major spatiotemporal features of the 7.5-yr (cf. Figs. 5 and 9a) and 22-yr (cf. Figs. 8 and 9c) observed oscillations, but the spatial pattern of the model's 11-yr mode is not consistent with that of the observed 13-yr signal (cf. Figs. 6 and 9b). In particular, the highest-frequency subdecadal signal, with a period of 7-7.5 $\mathrm{yr}$ in both the model and observations, is fully described by the leading three EOFs of this oscillation's reconstructed time series (for the model, these EOFs account for $80 \%, 11 \%$, and $6 \%$ of the total reconstructed variance, respectively). The leading EOFs in both cases are tripolar, with some differences in their detailed spatial patterns, such as the area of positive values off the east coast of the United States being located slightly more eastward in the CGCMt47 run compared to that in the observed tripole. Similar differences exist between EOF-2 and -3 of the observed and modeled 7-7.5-yr signal reconstructions.

The comparison between the actual and simulated 22-23-yr signals is about as favorable as the one for the 7-7.5-yr signal above. Namely, for both the modeled and observed 22-23-yr signals, two EOF patterns (which account for $83 \%$ and $15 \%$ of the total reconstructed variance in the model simulation) describe the anomaly propagation along the coast of the United States; however, the details of these patterns are, once again, somewhat different, especially for the tripolar EOF-1, which is characterized by a less pronounced center lobe in the model simulation (Fig. 9c, left) compared to the observed one (Fig. 8, left). These examples illustrate the subjective character of matching the observed and simulated signals based solely on the visual similarity of their spatiotemporal properties. We will introduce more objective similarity measures below in section $3 \mathrm{~b}(2)$.

Finally, while the CGCMt47 model did simulate a statistically significant 11-yr oscillation, the pattern and time dependence of this signal (Fig. 9b) are very different from those of the observed 13-yr mode (Fig. 6). The observed signal is represented by a stationary tripole, while the simulated 11-yr signal has a propagating character; it is described by two EOFs, which account for $68 \%$ and $31 \%$ of this signal's total reconstructed variance. This signal is in fact very similar to the simulated $23-y r$ mode. We conjecture that while the observed 13- and 22-yr signals represent distinct oscillations, the 11-yr oscillation in the CGCMt47 is a harmonic of its primary $23-\mathrm{yr}$ signal.

In summary, while many models reproduce the quasiperiodic oscillations whose time scales and spatial patterns overlap with the observed ones, there is a lack of detailed visual correspondence between the observed and simulated decadal-to-interdecadal signals. To develop an objective and uniform measure for model-todata comparison, we need to "coarse grain" our analysis and examine the zero-order variability in the three observationally motivated frequency bands, rather than look into the fine details of the spatiotemporal dependencies of the observed and simulated signals. This is done in section $3 b(2)$. 


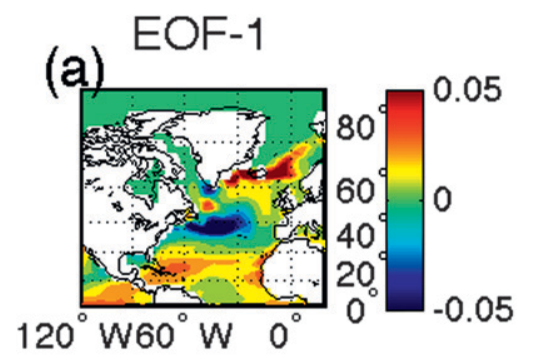

(b)

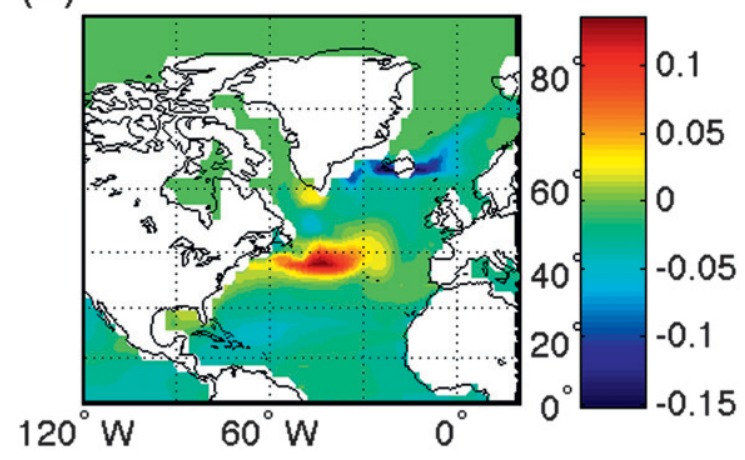

(c)

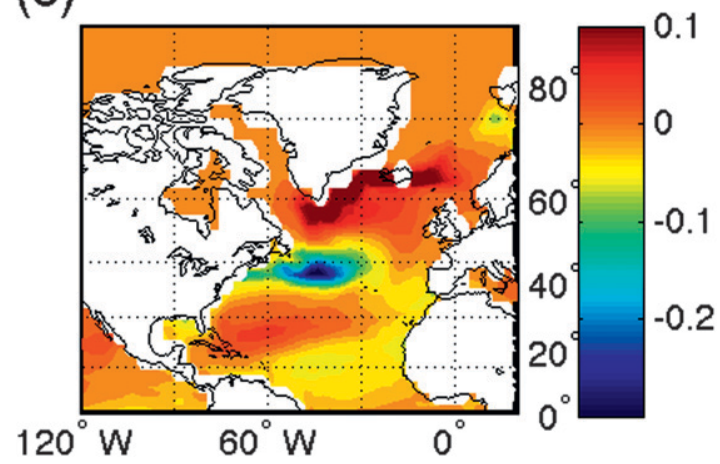

EOF-2

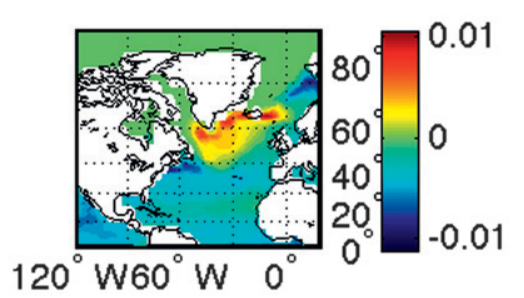

$120^{\circ} \mathrm{W} 60^{\circ} \mathrm{W} 0$

EOF-2
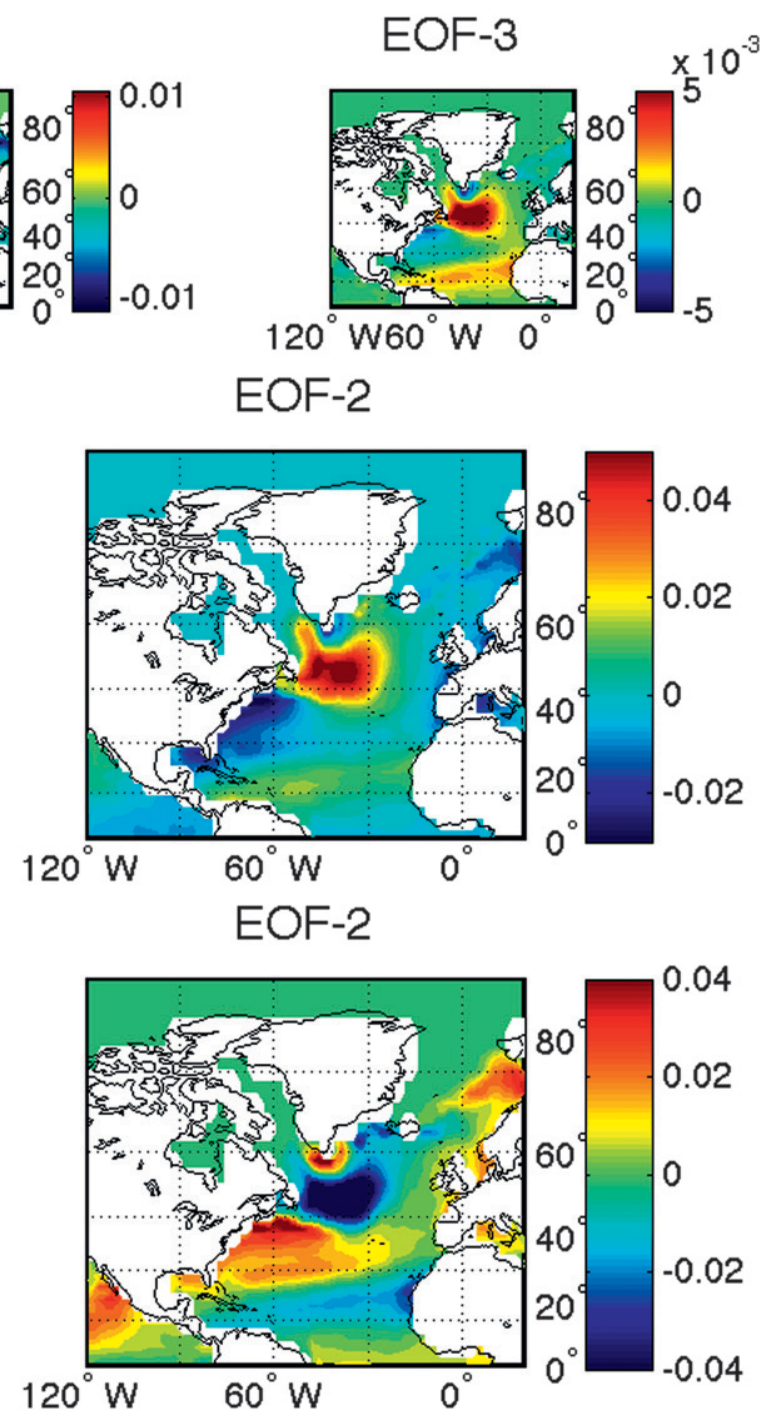

FIG. 9. Leading EOFs of RCs based on the M-SSA analysis of the North Atlantic SSTs simulated by CGCMt47. Three statistically significant signals are identified and their patterns plotted in the corresponding rows: (a) 7-, (b) 11-, and (c) 23-yr signals.

\section{2) SPATIAL CORRELATION AND VARIANCE RATIOS}

In developing uniform measures of similarity between the models and observations, we bandpass filtered both the observed and simulated North Atlantic SST datasets in the three frequency ranges defined above [see section $2 b(3)$ for the details of the filter], namely $5-10,10-15$, and $15-30 \mathrm{yr}$; recall that these ranges were chosen because they contained the periods of distinct signals identified by M-SSA analysis of the SST anomalies in the observations and in many of the models. We then computed and compared, for each of the three bands, the leading EOF of the model-simulated bandpass-filtered SSTs with that of the observed bandpass-filtered SST.
To do so, we interpolated each model's output onto the observational data grid and computed (i) the spatial correlation and (ii) the root-mean-square (RMS) distance between their respective dimensional EOF patterns (the dimensional EOFs were obtained by projecting the original dataset onto its leading PC normalized to have the unit variance), as well as (iii) the ratio of the modeledto-observed leading-PC variances (the latter ratio is also equal to the ratio of the squared lengths of the corresponding dimensional EOF vectors). We discuss our spatial correlation and variance ratio comparison here; see the supplemental materials for this paper for the RMSdistance results.

We estimated the significance of the spatial correlations $c$ relative to the null hypothesis of the 0 correlation 


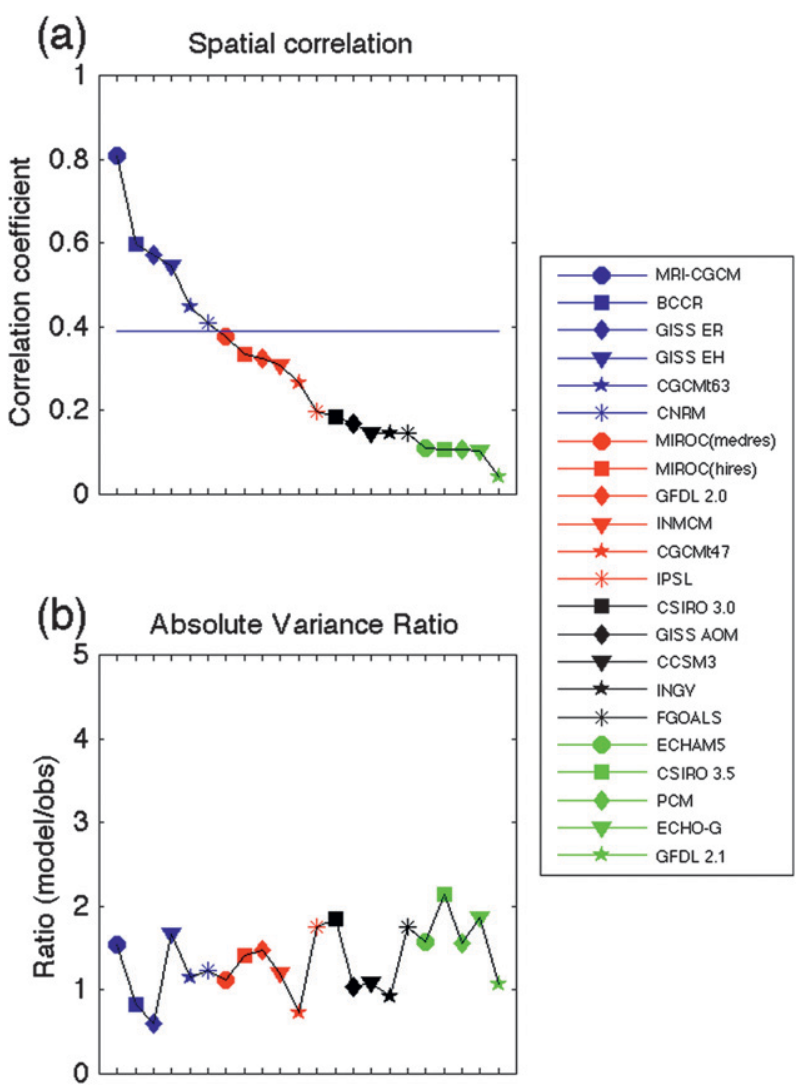

FIG. 10. Performance of the CMIP-3 models in simulating the observed SST variability in the 5-10-yr band: (a) spatial correlation between the leading EOFs of the simulated and observed bandpassfiltered data and (b) ratio of the absolute variances of these EOFs. The horizontal line in (a) represents the $t$-test-based $5 \%$ significance level for the null hypothesis of 0 correlation; in this test, the number $N$ of effective spatial degrees of freedom $N=17$ was set to the number of the observed SSTs leading EOFs that cumulatively account for $95 \%$ of the SST's total variance.

using the $t$ test, with $t=c \sqrt{(N-2) /\left(1-c^{2}\right)}$, and the number of degrees of freedom $N=17$ set to the number of the observed North Atlantic raw SST EOFs, which jointly account for $95 \%$ of the total SST variance. The two-sided 5\% significance level computed based on the $t$ statistic above corresponds to $|c| \approx 0.4$, so the correlations whose absolute value exceeds 0.4 are statistically significant at the $5 \%$ level.

\section{(i) High-frequency band (5-10 yr)}

Figure 10 shows the spatial correlation and absolute variance ratio for all models in the high-frequency (5$10 \mathrm{yr}$ ) band. In general, this band is best represented by CMIP3 models in terms of their ability to reproduce the observed variability. In particular, six models exhibit patterns whose spatial correlation with the observed pattern exceeds the 5\% level threshold (these models are marked by capital $\mathrm{O}$ symbols in the $5-10-\mathrm{yr}$ column of Table 2), while five more models have spatial correlation values just below this threshold (lowercase o symbols in Table 2). Out of these 11 models, only two [GISS-EH and MIROC(hires); see Table 1 for definition of the model acronyms used] do not exhibit the statistically significant M-SSA mode in the 5-10-yr band. Furthermore, the magnitude of the simulated variability in this band is consistent with the observed variance, within a factor of 2 ; that is, the variance ratios are between 0.5 and 2 for all of the 11 "skillful" models (note, however, that such a spread of variance ratios results in fairly high RMS distances between the observed and simulated patterns; see the supplemental materials for this paper).

\section{(ii) Medium-frequency band (10-15 yr)}

This band turned out to be the most problematic for the CMIP3 models (see Fig. 11 and third column of Table 2). A single model (INGV) simulates well the pattern of the dominant observed variability in this band, albeit its variance is only about $1 / 3$ of the observed. The next four models with correlations just below the $5 \%$ threshold have reasonable variance ratios close to one, but in just one case (GFDL2.1) is there also a statistically significant M-SSA mode within this band. Therefore, the majority of the significant M-SSA modes found within this band have patterns different from the observed ones [see also the CGCMt47 example in section 3b(1)], while the models that do simulate reasonable patterns of variability in this band are generally characterized by a noisierthan-observed pattern of behavior (so that the simulated oscillatory signal, if any, has a wide enough bandwidth that the M-SSA is unable to identify a frequency-localized statistically significant pair).

\section{(iii) Low-frequency band (15-30 yr)}

The results for this band are shown in Fig. 12 (see also the fourth column in Table 2). Nine of the models produced signals whose patterns are fairly highly correlated with the observed pattern, and whose variance ratios are reasonably close to one. Three of these models (CGCMt47, CNRM, and GISS-AOM) also have a statistically significant oscillation detected by the M-SSA in this band; hence, these models reproduce well both the variance and the spatiotemporal character of the observed signal. The remaining six skillful models that match the observed patterns and variances, but do not have a significant M-SSA mode within this band, thus differ from the observations in that they have less structured spectra corresponding to generally noisier (and, hence, less predictable) variability.

We shall return to the synthesis of the above results across all of the three bands in section 4 . Before doing 


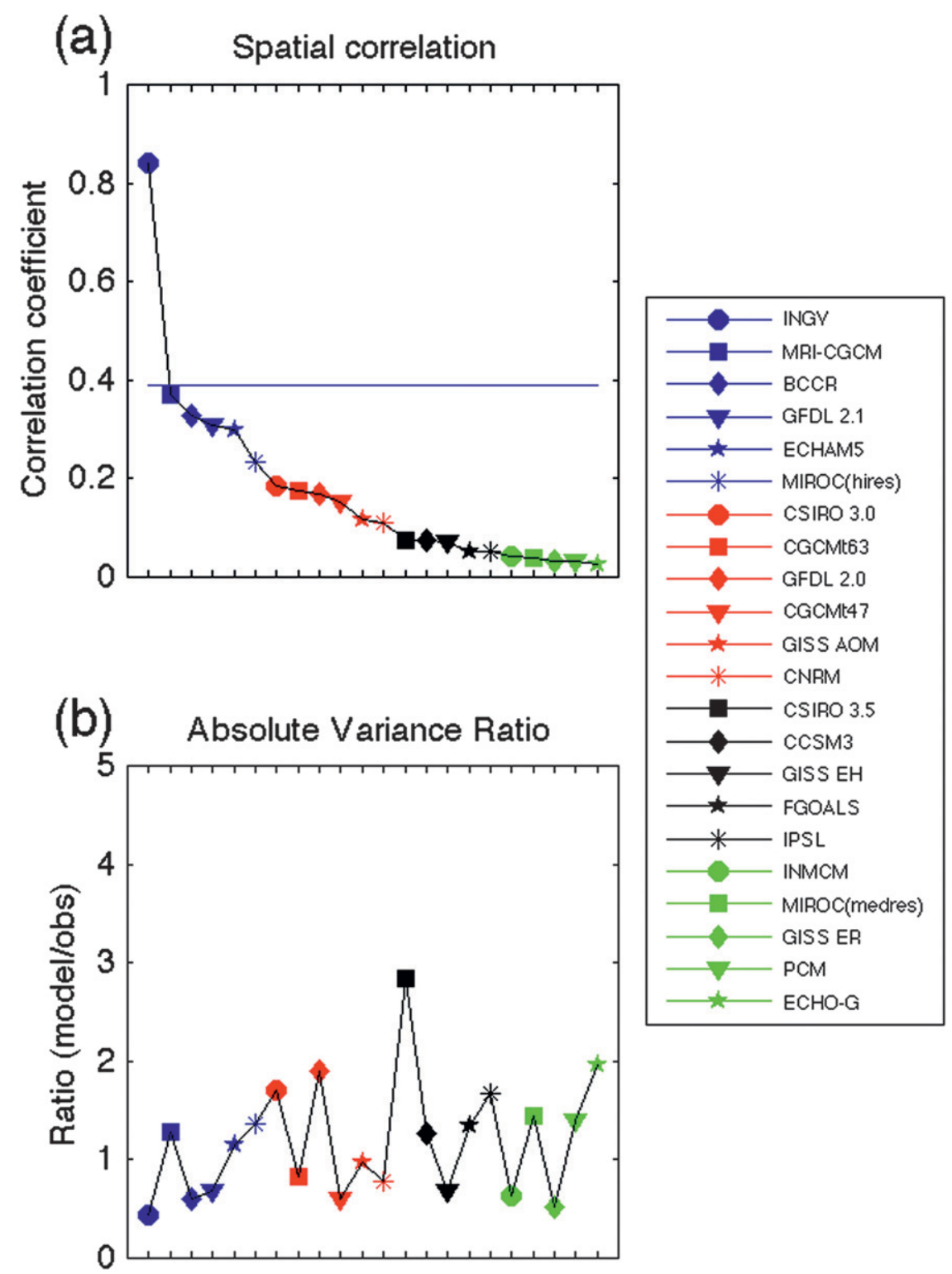

FIG. 11. As in Fig. 10, but for the 10-15-yr band.

so, we note here that the results shown in Figs. 10-12 are based on a single simulation of each model. The sensitivity of this analysis to sampling variations present in different model realizations is addressed in the supplemental materials for this paper. In particular, we find, based on a few case studies, that the typical spread of the spatial correlation values between the simulated and observed patterns associated with the model sampling is on the order of \pm 0.1 . We therefore conclude that the model classification in Figs. 10a-12a using the spatial correlation of leading bandpass-filtered signals is relatively robust with respect to the model sampling in that the group of leading models is well separated from the trailing ones, and the models ranked near the top in terms of this performance measure are likely to stay near the top irrespective of the realization considered.

\section{Summary and discussion}

We studied North Atlantic SST interannual-tointerdecadal variations in observations (Kaplan et al. 1998; Rayner et al. 2006) and simulations of the global coupled general circulation models that compose phase 3 of the WCRP's Coupled Model Intercomparison Project (CMIP3; see Table 1). Multichannel singular spectrum analysis (M-SSA) in the phase space of the leading EOFs of the observed SSTs (Fig. 1) identifies three distinct oscillations (Figs. 2 and 3) with periods of approximately 


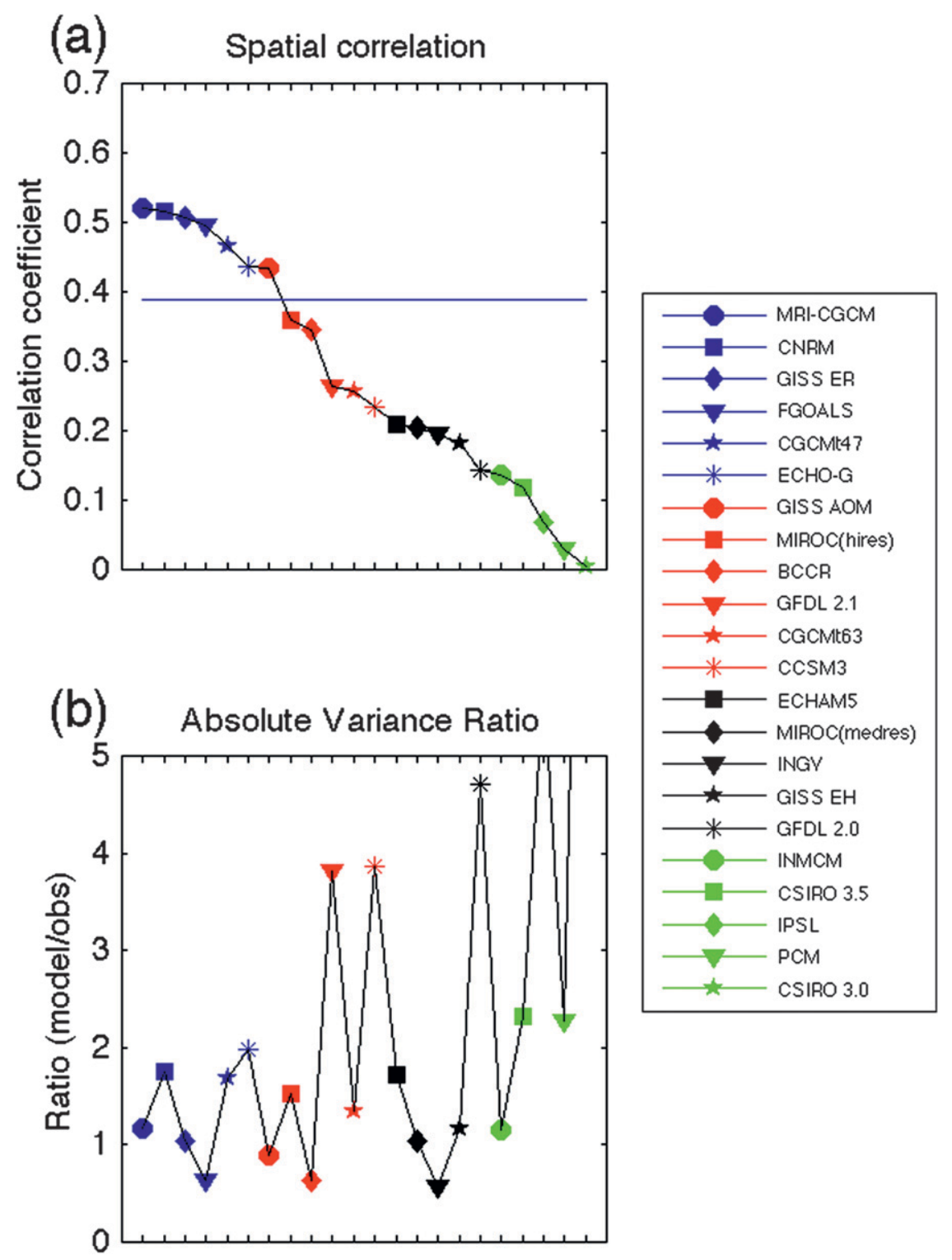

FIG. 12. As in Fig. 10, but for the 15-30-yr band.

$7.5,13$, and $22 \mathrm{yr}$; these oscillations have spatial patterns that bear certain geographical similarities but, nonetheless, exhibit distinctive spatiotemporal characteristics (Figs. 4-8). The periods and spatial patterns of the three signals are consistent with previous studies (Deser and Blackmon 1993; Moron et al. 1998; Kravtsov et al. 2008).

While many of the CMIP3 simulations are characterized by the M-SSA-identified quasi-oscillatory modes in one or more of the three observationally motivated bands (5-10, 10-15, and 15-30 yr; see Table 2), capturing the spatial patterns of the observed signals has turned out to be more challenging. Visual comparison of the dominant EOFs of the M-SSA-based reconstructions (RCs) for the observed and simulated signals (e.g., cf.
Figs. 4, 6, and 8 with Figs. 9a, 9b, and 9c, respectively) suggests general similarities between certain modes and identifies the most apparent differences between others, but is in many ways ambiguous. We therefore designed objective measures of model performance by considering leading EOFs of the 5-10-, 10-15-, and 15-30-yr bandpass-filtered SST data and computing the spatial correlations and variance ratios between the observed and simulated EOFs (Figs. 10-12 and Table 2); the RMS distance between the observed and EOFs is discussed in the supplemental materials for this paper.

Table 2 summarizes the inferred skill of the CMIP3 models in simulating the observed decadal-to-interdecadal North Atlantic SST variability. In particular, the models 
indicated by $\mathrm{O}$ and o symbols reproduce the observed SST patterns well, with spatial correlations above and only slightly below the $5 \%$ confidence level threshold, respectively (see Figs. 10-12). The X symbols mark the presence of a significant M-SSA pair for a given model and in a given frequency band. Note that the existence of such a pair unaccompanied by a high spatial-pattern correlation (i.e., $\mathrm{X}$ symbols unaccompanied by $\mathrm{O}$ or o symbols in Table 2) does not indicate a good match between the model and the observations, since the model essentially reproduces a different signal that happens to exhibit a given time scale. On the other hand, the models that are marked by the combination of $\mathrm{X}$ and $\mathrm{O}$ symbols (or o symbols) in a given frequency band can be considered highly skillful, since they capture not only the pattern and time scale of the observed variability, but also the detailed spectral structure within the specified band; the latter property is expressed by a model's ability to simulate a quasi-regular pattern of behavior indicated by the presence of a significant M-SSA pair. Finally, the models that capture the pattern of the observed bandpassfiltered SST variations, but fail to simulate a statistically significant M-SSA pair in this band, do possess some decadal skill, but are characterized by a noisier-thanobserved pattern of behavior there; hence, these models may underestimate the potential decadal predictability.

We have given a breakdown of the models' performance within each of the three frequency bands in section $3 \mathrm{~b}(2)$. The models best simulate the variability in the high-frequency, 5-10-yr band: 11 models reproduce well the observed SST pattern there, and 9 out of these 11 models [BCCR, CGSMt47, CGCMt63, CNRM, GFDL2.0, GISS-ER, INMCM, MIROC(medres), and MRI-CGCM] also capture the spectral character of the observed signal by exhibiting a significant M-SSA pair within this band. The 10-15-yr band turned out to be the most problematic, with only five of the models having simulated the pattern of the observed variations to some extent (spatial correlations here are generally lower than those in the 5-10-yr band) and only one of these five (GFDL2.1) is characterized by the presence of a significant M-SSA pair. The performance of the models in the low-frequency $15-30$-yr band is intermediate: nine models capture the observed patterns, while three of these nine models (CGCMt47, CNRM, and GISS-AOM) exhibit a significant M-SSA pair within this band. In each of the above skillful cases, the models also capture reasonably well, within a factor of 2 , the variance of the observed signals within each band: the simulated-to-observed signals variance ratios are within $0.5-2$.

It is tempting to identify the models that perform best across all the three bands considered. Two of the models (BCCR and MRI-CGCM) capture the patterns of the variability in all three bands; however, both of these models exhibit a significant M-SSA pair in the highfrequency 5-10-yr band only. Three models (CGCMt47, CNRM, and GISS-ER) simulate well the observed patterns in two bands, namely in the high-frequency 5-10-yr and low-frequency 15-30-yr bands; the former two models also possess a significant M-SSA pair in both of these bands, while the latter model does in the high-frequency band only. The rest of the models capture the observed variability in only one of the three frequency bands, as discussed above.

There are a number of possible dynamical explanations for why certain models perform better than others in reproducing the observed decadal variability in the North Atlantic; see Dijkstra and Ghil (2005) for a review of candidate dynamical mechanisms. One possibility is that the simulated decadal variability is directly linked to the modeled time-mean ocean state (see, e.g., Kravtsov and Ghil 2004). We took the initial steps in checking this hypothesis by comparing the model ranks based on the similarity of the simulated and observed climatological SSTs with the model decadal-variability ranks recorded in Figs. 10-12, but we were unable to obtain conclusive results (see the supplemental materials for this paper). Another possibility is that the spatial patterns of the atmospheric variability dictate some of the spatial structure of the SST variability (see, e.g., Saravanan and McWilliams 1998). Figure 13 shows regression in the maps of the SST and sea level pressure (SLP) fields on the leading normalized PCs of the North Atlantic bandpass-filtered SST anomalies, for all of the three bands considered. The SLP patterns are clearly coherent with the SST patterns, and consistent with the ocean forcing the atmosphere, rather than vice versa. This ocean forcing may affect the time dependence of the atmospheric patterns, and, if the latter patterns are not realistically simulated in a model, they may feed back on and introduce corresponding errors into simulated SST patterns. In summary, it may be possible argue that the differences in the spatial patterns of SST variability among the models could be tied to more realistic or less realistic atmospheric patterns of variability in these models.

Our results have implications for the rapidly developing field of decadal climate prediction (Meehl et al. 2009). The idea is to initialize climate models with the best available observationally based estimate of the current climate state and run the models forward for a few decades to predict the detailed climate evolution during this period. The pioneering efforts of Smith et al. (2007), Keenlyside et al. (2008), and Pohlmann et al. (2009) show improved skill in decadal forecasts through the initialization relative to the ensemble forecasts from arbitrary initial conditions; these studies rationalize the 
(a) EOF-1 of 7-year signal

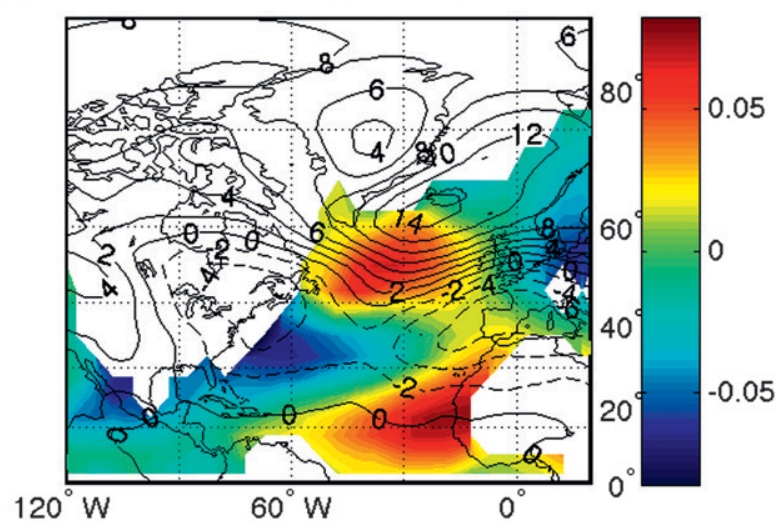

\section{(b) EOF-1 of 13-year signal}

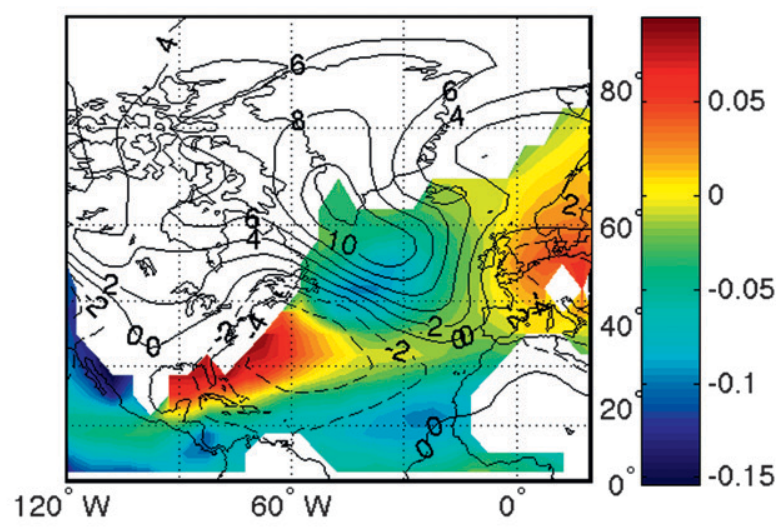

(c) EOF-1 of 22-year signal

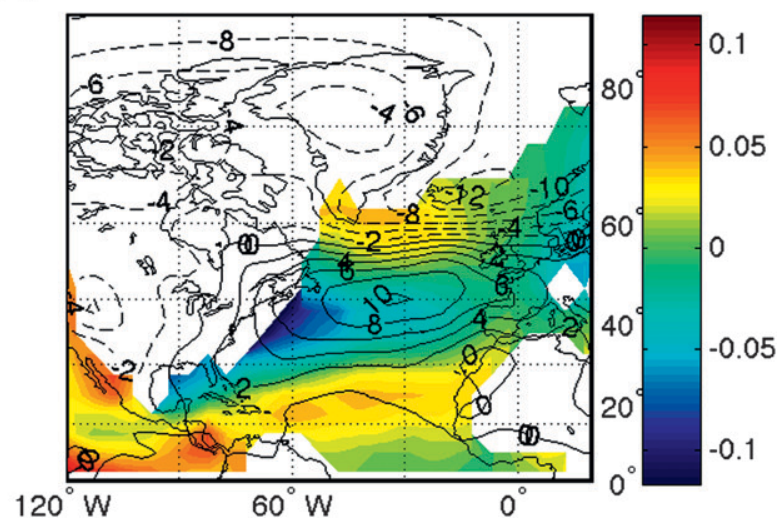

FIG. 13. Regression maps of the normalized leading PC of the observed bandpass-filtered North Atlantic SST variability onto SST (color shading, ${ }^{\circ} \mathrm{C}$ ) and SLP (contours, mb): (a) 5-10-, (b) 1015-, and (c) 15-30-yr bands. SLP data were taken from 1949-2007 National Centers for Environmental Prediction-National Center for Atmospheric Research (NCEP-NCAR) reanalysis (Kalnay et al. 1996). recent observed slowing down of the surface warming over the Atlantic Ocean as the effect of intrinsic climate variability. Knight et al. (2009) presented similar arguments in discussing the observed flattening of the global temperature time series over the past decade.

Meehl et al. (2009) noted that the improved decadal skill through proper initialization does not necessarily bear upon the model's ability to accurately simulate quasiperiodic decadal climate signals, and may result from the assimilation of persistent climatic features, such as longlived anomalies in the upper-ocean heat content. However, it is safe to assume that the models that are skillful in reproducing the observed decadal signals, as outlined in Table 2 and our discussion above, let us call these models group I, will have a better level of decadal skill than those that are not (group II). It would be interesting to assess the quantitative contributions of the models' ability to accurately simulate the observed internal variability to the decadal skill by comparing the decadal prediction performance of the two groups of models above in CMIP5-coordinated decadal predictability experiments (Taylor et al. 2008; Meehl et al. 2009; information is also available online at www.pcmdi.llnl.gov/). In case these two groups of models will turn out to be characterized by markedly different decadal skill, the theoretical question of the dynamical mechanisms governing the intrinsic decadal variations, and the way these mechanisms are represented in various climate models, will need to be revisited and addressed in more detail. An appealing way of doing so would be via the hierarchical approach advocated for by Ghil and Robertson (2000); in this approach, one scans back and forth between climate models of varying complexity, from idealized models that concentrate on a small subset of dynamical processes on one end to highly resolved detailed GCMs on the other.

Acknowledgments. We are grateful to two anonymous reviewers for their excellent and constructive comments that helped to improve this manuscript. We acknowledge the modeling groups, the Program for Climate Model Diagnosis and Intercomparison (PCMDI), and the WCRP's Working Group on Coupled Modelling (WGCM) for their roles in making available the WCRP CMIP3 multimodel dataset. Support of this dataset is provided by the Office of Science, U.S. Department of Energy. This research was also supported by the Office of Science (BER), U.S. Department of Energy Grant DE-FG02-07ER64428.

\section{REFERENCES}

Allen, M. R., 1992: Interactions between the atmosphere and oceans on time-scales of weeks to years. Ph.D. thesis, University of Oxford, $202 \mathrm{pp}$. 
Boer, G. J., and S. J. Lambert, 2001: Second order space-time climate difference statistics. Climate Dyn., 17, 213-218.

Broomhead, D. S., and G. P. King, 1986: Extracting qualitative dynamics from experimental data. Physica D, 20, 217-236.

Christiano, L. J., and T. J. Fitzgerald, 1999: The band pass filter. Federal Reserve Bank of Cleveland Working Paper 9906, 71 pp. [Available online at http://ideas.repec.org/p/fip/fedcwp/9906. html.]

DelSole, T., 2001: Optimally persistent patterns in time-varying fields. J. Atmos. Sci., 58, 1341-1356.

_ 2006: Low-frequency variations of surface temperature in observations and simulations. J. Climate, 19, 4487-4507.

Delworth, T. L., and M. E. Mann, 2000: Observed and simulated multidecadal variability in the Northern Hemisphere. Climate Dyn., 16, 661-676.

—, R. Zhang, and M. E. Mann, 2007: Decadal to centennial variability of the Atlantic from observations and models. Past and Future Changes of the Oceans Meridional Overturning Circulation: Mechanisms and Impacts, Geophys. Monogr., Vol. 173, Amer. Geophys. Union, 131-148.

Deser, C., and M. Blackmon, 1993: Surface climate variations over the North Atlantic Ocean during winter 1900-1989. J. Climate, 6, 1743-1753.

Dijkstra, H. A., and M. Ghil, 2005: Low-frequency variability of the large-scale ocean circulation: A dynamical systems approach. Rev. Geophys., 43, RG3002, doi:10.1029/2002RG000122.

Dong, B., and R. T. Sutton, 2005: Mechanism of interdecadal thermohaline circulation variability in a coupled ocean-atmosphere GCM. J. Climate, 18, 1117-1135.

$[,-$, and A. A. Scaife, 2006: Multidecadal modulation of El Niño-Southern Oscillation (ENSO) variance by Atlantic Ocean sea surface temperatures. Geophys. Res. Lett., 33, L08705, doi:10.1029/2006GL025766.

Dufresne, J. L., and S. Bony, 2008: An assessment of the primary sources of spread of global warming estimates from coupled atmosphere-ocean models. J. Climate, 21, 5135-5144.

Elsner, J. B., and A. A. Tsonis, 1996: Singular Spectrum Analysis: A New Tool in Time Series Analysis. Springer, 177 pp.

Enfield, D. B., A. M. Mestas-Nuñez, and P. J. Trimble, 2001: The Atlantic multidecadal oscillation and its relation to rainfall and river flows in the continental U.S. Geophys. Res. Lett., 28, 277-280.

Feliks, Y., M. Ghil, and A. W. Robertson, 2010: Oscillatory climate modes in the Eastern Mediterranean and their synchronization with the North Atlantic Oscillation. J. Climate, in press.

Ghil, M., and R. Vautard, 1991: Interdecadal oscillations and the warming trend in global temperature time series. Nature, $\mathbf{3 0 5}$, 324-327.

- and A. W. Robertson, 2000: Solving problems with GCMs: General circulation models and their role in the climate modeling hierarchy. General Circulation Model Development: Past, Present and Future, D. Randall, Ed., Academic Press, 285-325.

_- and Coauthors, 2002: Advanced spectral methods for climatic time series. Rev. Geophys., 40, 3.1-3.41, doi:10.1029/ 2000GR000092.

Guilyardi, E., 2006: El Niño-mean state-seasonal cycle interactions in a multi-model ensemble. Climate Dyn., 26, 329-348, doi:10.1007/s00382-005-0084-6.

Hasselmann, K., 1976: Stochastic climate models. Part 1: Theory. Tellus, 28, 473-485.

Jun, M., R. Knutti, and D. W. Nyvhka, 2008: Local eigenvalue analysis of CMIP3 climate model errors. Tellus, 60A, 992-1000.

Kalnay, E., and Coauthors, 1996: The NCEP/NCAR 40-Year Reanalysis Project. Bull. Amer. Meteor. Soc., 77, 437-471.
Kaplan, A., M. Cane, Y. Kushnir, A. Clement, M. Blumenthal, and B. Rajagopalan, 1998: Analyses of global sea surface temperature 1856-1991. J. Geophys. Res., 103, 18 56718589.

Keenlyside, N., M. Latif, J. Jungclaus, Kornblueh, and E. Roeckner, 2008: Advancing decadal-scale climate predictions in the North Atlantic sector. Nature, 453, 84-88.

Keppenne, C. L., and M. Ghil, 1993: Adaptive filtering and prediction of noisy multivariate signals: An application to subannual variability in atmospheric angular momentum. Int. J. Bifurcat. Chaos, 3, 625-634.

Knight, J., and Coauthors, 2009: Do global temperature trends over the last decade falsify climate predictions? Bull. Amer. Meteor. Soc., 90 (Suppl.), S22-S23.

Kondrashov, D., Y. Feliks, and M. Ghil, 2005: Oscillatory modes of extended Nile River records (A.D. 622-1922). Geophys. Res. Lett., 32, L10702, doi:10.1029/2004GL022156.

Kravtsov, S., and M. Ghil, 2004: Interdecadal variability in a hybrid coupled ocean-atmosphere-sea ice model.J. Phys. Oceanogr., 34, 1756-1775.

W. K. Dewar, P. Berloff, J. C. McWilliams, and M. Ghil, 2008: North Atlantic climate variability in coupled models and data. Nonlinear Processes Geophys., 15, 13-24.

Lin, J.-L., 2007: The double-ITCZ problem in IPCC AR4 coupled GCMs: Ocean-atmosphere feedback analysis. J. Climate, 20, 4497-4525.

Mann, M. E., and K. A. Emanuel, 2006: Atlantic hurricane trends linked to climate change. Eos, Trans. Amer. Geophys. Union, 87 (233), 238-241.

Meehl, G. A., C. Covey, T. Delworth, M. Latif, B. McAvaney, J. F. B. Mitchell, R. J. Stouffer, and K. E. Taylor, 2007: The WCRP CMIP3 multimodel dataset: A new era in climate change research. Bull. Amer. Meteor. Soc., 88, 1383-1394.

— , and Coauthors, 2009: Decadal prediction: Can it be skillful? Bull. Amer. Meteor. Soc., 90, 1467-1485.

Min, S.-K., and A. Hense, 2006: A Bayesian approach to climate model evaluation and multi-model averaging with an application to global mean surface temperatures from IPCC AR4 coupled climate models. Geophys. Res. Lett., 33, L08708, doi:10.1029/2006GL025779.

Mo, K. C., J. K. Schemm, H. M. H. Juang, R. W. Higgins, and Y. Song, 2005: Impact of model resolution on the prediction of summer precipitation over the United States and Mexico. J. Climate, 18, 3910-3927.

Moron, V., R. Vautard, and M. Ghil, 1998: Trends, interdecadal and interannual oscillations in global sea-surface temperatures. Climate Dyn., 14, 545-569.

Murphy, J. M., D. M. H. Sexton, D. N. Barnett, G. S. Jones, M. J. Webb, M. Collins, and D. A. Stainforth, 2004: Quantification of modeling uncertainties in a large ensemble of climate change simulations. Nature, 430, 768-772.

Plaut, G., and R. Vautard, 1994: Spells of low-frequency oscillations and weather regimes in the Northern Hemisphere. J. Atmos. Sci., 51, 210-236.

, M. Ghil, and R. Vautard, 1995: Interannual and interdecadal variability in 335 years of central England temperatures. Science, 268, 710-713.

Pohlmann, H., J. H. Jungclaus, A. Köhl, and J. Marotzke, 2009: Initializing decadal climate predictions with the GECCO oceanic synthesis: Effects on the North Atlantic. J. Climate, 22, 3926-3938.

Preisendorfer, R. W., 1988: Principal Component Analysis in Meteorology and Oceanography. Elsevier, 425 pp. 
Press, W. H., S. A. Teukolsky, W. T. Vetterling, and B. P. Flannery, 1992: Numerical Recipes in C: The Art of Scientific Computing. 2nd ed. Cambridge University Press, 994 pp.

Rayner, N. A., P. Brohan, D. E. Parker, C. K. Folland, J. J. Kennedy, M. Vanicek, T. Ansell, and S. F. B. Tett, 2006: Improved analyses of changes and uncertainties in marine temperature measured in situ since the mid-nineteenth century: The HadSST2 dataset. J. Climate, 19, 446-469.

Rotstayn, L. D., and U. Lohmann, 2002: Tropical rainfall trends and the indirect aerosols effect. J. Climate, 15, 2103-2116.

Saravanan, R., and J. C. McWilliams, 1998: Advective oceanatmosphere interaction: An analytical stochastic model with implications for decadal variability. J. Climate, 11, 165-188.

Smith, D., S. Cusack, A. Colman, C. Folland, G. Harris, and J. Murphy, 2007: Improved surface temperature prediction for the coming decade from a global circulation model. Science, 317, 796799.

Sun, D. Z., and Coauthors, 2006: Radiative and dynamical feedbacks over the equatorial cold tongue: Results from nine atmospheric GCMs. J. Climate, 19, 4059-4074.

Sutton, R. T., and M. R. Allen, 1997: Decadal predictability of North Atlantic sea surface temperature and climate. Nature, 388, 563-567.

Taylor, K. E., 2001: Summarizing multiple aspects of model performance in a single diagram. J. Geophys. Res., 106 (D7), 71837192.
- R. J. Stouffer, and G. A. Meehl, 2008: A summary of the CMIP5 experimental design. International CLIVAR Project Office, Southampton, United Kingdom, 30 pp. [Available online at www.clivar.org/organization/wgcm/references/Taylor_CMIP5. pdf.]

Vautard, R., and M. Ghil, 1989: Singular spectrum analysis in nonlinear dynamics, with applications to paleoclimatic time series. Physica D, 35, 395-424.

_ toolkit for short, noisy and chaotic series. Physica D, 58, 95126.

Wallace, J. M., Y. Zhang, and K. H. Lau, 1993: Structure and seasonality of interannual and interdecadal variability of the geopotential height and temperature fields in the Northern Hemisphere troposphere. J. Climate, 6, 2063-2082.

Zhang, R., and T. L. Delworth, 2006: Impact of Atlantic multidecadal oscillations on India/Sahel rainfall and Atlantic hurricanes. Geophys. Res. Lett., 33, L17712, doi:10.1029/ 2006 GL026267.

,$- \ldots$, and I. M. Held, 2007: Can the Atlantic Ocean drive the observed mulitdecadal variability in Northern Hemisphere mean temperature? Geophys. Res. Lett., 34, L02709, doi:10.1029/ 2006 GL028683.

Zhou, T., B. Wu, and B. Wang, 2009: How well do atmospheric general circulation models capture the leading modes of the interannual variability of the Asian-Australian monsoon? J. Climate, 22, 1159-1173. 